\title{
Prevalence of persistent blood eosinophilia: relation to outcomes in patients with COPD
}

\author{
Ciro Casanova1, Bartolome R. Celli², Juan P. de-Torres ${ }^{3}$, \\ Cristina Martínez-Gonzalez ${ }^{4}$, Borja G. Cosio $0^{5,6}$, Victor Pinto-Plata ${ }^{7}$, \\ Pilar de Lucas-Ramos ${ }^{8}$, Miguel Divo $^{2}$, Antonia Fuster ${ }^{9}$, \\ Germán Peces-Barba ${ }^{6,10}$, Myriam Calle-Rubio ${ }^{10}{ }^{11}$, Ingrid Solanes ${ }^{12}$, \\ Ramón Aguero ${ }^{13}$, Nuria Feu-Collado ${ }^{14}$, Inmaculada Alfageme ${ }^{15}$, \\ Alfredo De Diego ${ }^{16}$, Amparo Romero ${ }^{17}$, Eva Balcells ${ }^{18}$, Antonia Llunell ${ }^{19}$, \\ Juan B. Galdiz ${ }^{20}$, Margarita Marin ${ }^{21}$, Amalia Moreno ${ }^{22}$, Carlos Cabrera ${ }^{23}$, \\ Rafael Golpe ${ }^{24}$, Celia Lacarcel ${ }^{25}$, Joan B. Soriano (ib ${ }^{26}$, \\ José Luis López-Campos ${ }^{6,27}$, Juan J. Soler-Cataluña ${ }^{28}$ and José M. Marin (10 ${ }^{29}$
}

@ERSpublications

The stability of blood eosinophils $\geqslant 300$ cells per $\mu \mathrm{L}$ is low in COPD patients and it does not confer a poor prognosis http://ow.ly/TwGX30etVIy

Cite this article as: Casanova C, Celli BR, de-Torres JP, et al. Prevalence of persistent blood eosinophilia: relation to outcomes in patients with COPD. Eur Respir J 2017; 50: 1701162 [https://doi.org/10.1183/ 13993003.01162-2017].

ABSTRACT The impact of blood eosinophilia in chronic obstructive pulmonary disease (COPD) remains controversial.

To evaluate the prevalence and stability of a high level of blood eosinophils $\left(\geqslant 300\right.$ cells $\left.\mu \mathrm{L}^{-1}\right)$ and its relationship to outcomes, we determined blood eosinophils at baseline and over 2 years in 424 COPD patients (forced expiratory volume in $1 \mathrm{~s}$ (FEV1) 60\% predicted) and 67 smokers without COPD from the CHAIN cohort, and in 308 COPD patients (FEV1 60\% predicted) in the BODE cohort. We related eosinophil levels to exacerbations and survival using Cox hazard analysis.

In COPD patients, $15.8 \%$ in the CHAIN cohort and $12.3 \%$ in the BODE cohort had persistently elevated blood eosinophils at all three visits. A significant proportion (43.8\%) of patients had counts that oscillated above and below the cut-off points, while the rest had persistent eosinophil levels $<300$ cells $\mu \mathrm{L}^{-1}$. A similar eosinophil blood pattern was observed in controls. Exacerbation rates did not differ in patients with and without eosinophilia. All-cause mortality was lower in patients with high eosinophils compared with those with values $<300$ cells $\mu \mathrm{L}^{-1}(15.8 \%$ versus $33.7 \%$; $\mathrm{p}=0.026)$.

In patients with COPD, blood eosinophils $\geqslant 300$ cells $\mu \mathrm{L}^{-1}$ persisting over 2 years was not a risk factor for COPD exacerbations. High eosinophil count was associated with better survival.

This article has supplementary material available from erj.ersjournals.com

Received: June 102017 | Accepted after revision: July 272017

Support statement: This study was funded by AstraZeneca. Funding information for this article has been deposited with the Crossref Funder Registry.

Conflict of interest: Disclosures can be found alongside this article at erj.ersjournals.com

Copyright OERS 2017 
Affiliations: ${ }^{1}$ Pulmonary Dept, Hospital Universitario Ntra Sra de La Candelaria, Tenerife, Spain. ${ }^{2}$ Pulmonary and Critical Care Dept, Brigham and Women's Hospital, Boston, MA, USA. ${ }^{3}$ Pulmonary Dept, Clínica Universidad de Navarra, Pamplona, Spain. ${ }^{4}$ Pulmonary Dept, Hospital Central de Asturias, Oviedo, Spain. ${ }^{5}$ Pulmonary Dept, Hospital Son Espases-IdISPa, Palma de Mallorca, Spain. ${ }^{6}$ CIBER de Enfermedades Respiratorias (CIBERES), Instituto de Salud Carlos III, Madrid, Spain. ${ }^{7}$ Baystate Medical Center, Springfield, MA, USA. ${ }^{8}$ Pulmonary Dept I, Hospital Gregorio Marañón, Madrid, Spain. ${ }^{9}$ Pulmonary Dept, Hospital Son Llátzer, Mallorca, Spain. ${ }^{10}$ Pulmonary Dept, Fundación Jimenez Díaz, Madrid, Spain. ${ }^{11}$ Pulmonary Dept, Hospital Clínico San Carlos, Medicine Dept, Faculty of Medicine, University Complutense of Madrid, Madrid, Spain. ${ }^{12}$ Pulmonary Dept, Hospital Santa Creu i Sant Pau, Universidad Autónoma de Barcelona, Barcelona, Spain. ${ }^{13}$ Pulmonary Dept, Hospital Marqués de Valdecilla, Santander, Spain. ${ }^{14}$ Pulmonary Dept, Hospital Universitario Reina Sofia, IMIBIC, UCO, Córdoba, Spain. ${ }^{15}$ Pulmonary Dept, Hospital Universitario de Valme, Sevilla, Spain. ${ }^{16}$ Pulmonary Dept, Hospital Universitario de la Fe, Valencia, Spain. ${ }^{17}$ Pulmonary Dept, Hospital de Manacor, Mallorca, Spain. ${ }^{18}$ Pulmonary Dept, Hospital del Mar, Barcelona, Spain. ${ }^{19}$ Pulmonary Dept, Hospital de Tarrasa, Tarrasa, Spain. ${ }^{20}$ Pulmonary Dept, Hospital de Cruces, Bilbao, Spain. ${ }^{21}$ Pulmonary Dept, Hospital General de Castellon, Castellon, Spain. ${ }^{22}$ Pulmonary Dept, Hospital Parc Tauli, Sabadell, Barcelona, Spain. ${ }^{23}$ Pulmonary Dept, Hospital Dr Negrín, Las Palmas de Gran Canaria, Spain. ${ }^{24}$ Pulmonary Dept, Hospital Universitario Lucus Augusti, Lugo, Spain. ${ }^{25}$ Pulmonary Dept, Hospital Ciudad de Jaén, Jaén, Spain. ${ }^{26}$ Instituto de Investigación, Hospital Universitario de la Princesa-IISP, Madrid, Spain. ${ }^{27}$ Unidad MédicoQuirúrgica de Enfermedades Respiratorias, Instituto de Biomedicina de Sevilla (IBiS), Hospital Universitario Virgen del Rocío, Sevilla, Spain. ${ }^{28}$ Pulmonary Dept, Hospital Arnau de Vilanova, Valencia, Spain. ${ }^{29}$ Pulmonary Dept, Hospital Universitario Miguel Servet, IISAragon, CIBERES, Zaragoza, Spain.

Correspondence: Ciro Casanova, Pulmonary Dept and Research Unit, Hospital Universitario La Candelaria, Carretera del Rosario 145, 38010 Santa Cruz de Tenerife, Spain. E-mail: casanovacirolagmail.com

\section{Introduction}

Chronic obstructive pulmonary disease (COPD) is a complex and heterogeneous disease [1]. It has been proposed that the identification of clinical phenotypes using validated biomarkers may promote the development of targeted treatment strategies directed towards specific biological pathways [2, 3].

In patients with COPD, eosinophilic airway inflammation has been described during stable disease and exacerbations even after the exclusion of patients with any features of asthma $[4,5]$. In patients with stable COPD, there is a correlation between blood and sputum eosinophils that is modest; however, blood eosinophil levels have been used as a surrogate maker for airway eosinophils in these patients [6,7].

Recently, several post hoc pharmacological trials have shown that patients with higher blood eosinophil counts had a greater reduction in exacerbation rates with inhaled corticosteroid (ICS) therapy [8-12]. These results suggested that a high blood eosinophil count could represent a simple biomarker in clinical decision making. However, it is unclear what would be the threshold of blood eosinophils that might be relevant. Although some studies have observed a potential biomarker role for blood eosinophils using a low threshold level (similar to the normal range of healthy subjects of $\geqslant 150$ cells $\mu \mathrm{L}^{-1}$ ), other studies have only detected potential differences with higher circulating blood values $\left(\geqslant 280-300\right.$ cells $\left.\mu \mathrm{L}^{-1}\right)[8,12]$. The analysis of two observational cohorts supports the argument that relatively low blood eosinophil counts $\geqslant 150$ cells $\mu \mathrm{L}^{-1}$ are not associated with poor outcomes in $\operatorname{COPD}[6,13]$ and the prevalence of blood eosinophil levels in patients was similar to that observed in healthy subjects [6]. Importantly, all studies used a single cross-sectional measurement taken at baseline without subsequent validation, a concept that is in disagreement with the need to document persistently elevated values to confirm the diagnosis of blood eosinophilia [14].

Given the limited information about the prevalence of persistently elevated eosinophils in patients with COPD and smokers without COPD, and the relationship between persistently elevated eosinophil counts and outcomes in those patients, we assessed blood eosinophil count at baseline and longitudinally (annually over 2 years) in patients participating in the CHAIN (COPD History Assessment In SpaiN) and BODE (body mass index (B), degree of airflow obstruction (O), functional dyspnoea (D) and exercise capacity (E)) cohorts. We hypothesised that persistently elevated blood eosinophil levels would relate to exacerbations, hospitalisations and survival.

\section{Methods}

Subjects

CHAIN cohort

CHAIN is an ongoing observational study of 24 COPD cohorts enrolled in Spain [15]. COPD was defined by a smoking history $\geqslant 10$ pack-years and a post-bronchodilator forced expiratory volume in $1 \mathrm{~s}\left(\mathrm{FEV}_{1}\right) /$ forced vital capacity (FVC) $<0.7$ after $400 \mu \mathrm{g}$ albuterol. Patients were stable for at least 6 weeks and received optimal medical therapy. Exclusion criteria were uncontrolled comorbidities such as malignancy or other confounding diseases that could interfere with the study. The recruitment period was January 2010 to March 2012 (ClinicalTrials.gov: identifier NCT01122758). Data analysed in the present study came from the recruitment date up to December 15, 2015. Data were anonymised with hierarchical access 
control in order to guarantee that information was secure. All participants signed the informed consent approved by the ethics committees (Comité de Etica de la Investigación, Hospital Universitario la Candelaria, Tenerife; 258/2009).

\section{BODE cohort}

The study comprised most of the original 625 patients recruited for the BODE study between July 1997 and December 2011 and followed until December 2015 in the USA and Spain. The study was approved by the human review board at each site and all patients provided informed consent. The definition of COPD was similar to that of CHAIN, as published previously [16]. All patients were clinically stable and receiving therapy according to international guidelines [1].

Patients were not included in the study if they had a history of asthma or were being treated for asthma at the time of the clinical evaluation. In addition, patients were not included if they had $>15 \%$ increase in their baseline FEV1 after administration of albuterol. No selection was made based on any other biological marker, including eosinophil count.

\section{Blood eosinophils}

All participants had a minimum of three blood eosinophil measurements separated by at least 1 year. Blood eosinophils were measured using automated blood count analysis and were reported as cells per microlitre. A threshold value of 300 cells $\mu \mathrm{L}^{-1}$ was used to define blood eosinophilia, based on the relationship between that level and poor outcomes in cohort [13] and clinical studies [8, 12]. In addition, we quantified the levels of IgE in patients in the CHAIN cohort.

Based on the eosinophil count, the cohort was divided into three subgroups: patients with a persistently high blood eosinophil count $\left(\geqslant 300\right.$ cells $\left.\mu \mathrm{L}^{-1}\right)$ in the three measurements, patients with an intermittently variable eosinophil count (fluctuating between $\geqslant 300$ and $<300$ cells $\mu \mathrm{L}^{-1}$ ) in the three measurements and patients with a persistently low eosinophil count $\left(<300\right.$ cells $\left.\mu \mathrm{L}^{-1}\right)$ in the three measurements.

\section{Clinical and physiological measurements}

Trained staff obtained information on age, sex and body mass index at baseline and subsequent visits. A questionnaire was used to determine smoking status (current or ex-smoker) and smoking history (in pack-years).

Pulmonary function tests were performed following the American Thoracic Society guidelines [17]. Transfer coefficient of the lung for carbon monoxide was determined with the single-breath technique following international guidelines [18]. Arterial blood gases were measured while sitting and breathing room air. The 6-min walk distance (6MWD) was measured as the better of two walks separated by at least 30 min [19]. Dyspnoea was evaluated with the modified Medical Research Council (mMRC) scale [20]. FEV1, body mass index, 6MWD and mMRC values were integrated into the BODE index [16]. In CHAIN, the COPD Assessment Test questionnaire was self-administered with the supervision of the interviewer. Comorbidities were scored using the Charlson index [21].

\section{Outcomes}

Exacerbations were defined as a worsening of respiratory symptoms (dyspnoea, cough or sputum) that required the use of antibiotics, systemic corticosteroids or both, or necessitated emergency room visit or hospital admission [1]. Exacerbations were evaluated only in the CHAIN cohort.

All-cause mortality was recorded using information obtained from the family and then confirmed by reviewing medical records, as published previously [16].

\section{Statistical analysis}

Data are summarised as frequency for categorical variables, median (5th-95th percentile) for ordinal or nonnormal scale variables and mean $\pm \mathrm{sD}$ for normally distributed scale variables. Comparisons were made between groups using Pearson's Chi-squared test, the Kruskal-Wallis H-test or the Mann-Whitney U-test and one-way ANOVA or the t-test as appropriate. Kaplan-Meier analysis for survival due to all causes was performed with an eosinophil value of 300 cells $\mu \mathrm{L}^{-1}$. Finally, to predict the risk of death we performed Cox proportional hazard regression analyses with the same eosinophil threshold. Significance was established as two-tailed $\mathrm{p}<0.05$. Calculations were performed using SPSS version 21.0 (IBM, Armonk, NY, USA).

\section{Results}

Characteristics of the participants

We identified 424 COPD patients and 67 smokers without COPD from the CHAIN cohort and 308 COPD patients from the BODE cohort with three eosinophil measurements over 2 years (figure 1). 
The baseline characteristics for the CHAIN patients are shown in table 1. There were no differences between groups except for the IgE levels, which were higher in patients with persistently elevated eosinophil counts. The population included a broad range of airflow limitation and consisted mostly of men. A similar proportion of patients used inhaled anticholinergics, $\beta_{2}$-agonists and ICSs in both groups. On average, the patients reported relatively few symptoms, and scored low in the BODE index and Charlson index.

Table 1 also shows the baseline characteristics of the BODE cohort patients. There were no differences in any of the clinical and physiological variables in patients with and without persistently elevated blood eosinophils.

\section{Prevalence and longitudinal follow-up of blood eosinophil levels}

The distribution of blood eosinophil count was similar in smokers with and without COPD in the CHAIN cohort (figure 2a). Over time, the proportion of COPD patients and controls with a persistent blood eosinophil count $\geqslant 300$ cells. $\mu \mathrm{L}^{-1}$ was similar ( 15.8 and $14.9 \%$, respectively) (figure $2 \mathrm{~b}$ ). The same distribution and persistence was observed using thresholds of 150 or 350 cells. $\mu \mathrm{L}^{-1}$ (supplementary table S1). This analysis was not performed in the BODE cohort because there were no control subjects in this cohort. However, the proportion of patients who remained with high levels of blood eosinophils between the first and third measurements was similar in the CHAIN and BODE cohorts (45.6\% versus $46.3 \%$, respectively) (figure 1). Therapy with ICSs did not influence these results as the proportion of users of ICSs was similar in patients with persistently high, intermittently variable or persistently low blood eosinophils (supplementary table S2).

\section{Outcomes in patients with COPD}

There were no significant differences in baseline clinical and physiological characteristics between the COPD patients with persistently high blood eosinophil counts $\left(\geqslant 300\right.$ cells $\left.\mu \mathrm{L}^{-1}\right)$, compared with those with persistently low or intermittently variable eosinophil counts (tables 2 and 3). We observed similar results when we used different thresholds of $\geqslant 250$ and 350 cells $\mu \mathrm{L}^{-1}$ (data not shown).

In the CHAIN cohort, the median follow-up time after the eosinophils longitudinal pattern was established was 17 (14-22) months. During the first 12 months of follow-up, the proportions of patients with one or more moderate exacerbations and the distribution for persistently low, intermittently variable and persistently high blood eosinophil patterns were 53 (30.1\%), 31 (24.2\%) and 29 (22.8\%), respectively ( $\mathrm{p}=0.302)$. Among the exacerbators, only 39 (9\%) patients had two or more moderate exacerbations. The proportion of patients hospitalised was $7.4 \%$ for the persistently low eosinophil group, $6.3 \%$ for the intermittently variable eosinophil group and $2.4 \%$ for the persistently high eosinophil group ( $\mathrm{p}=0.157)$.

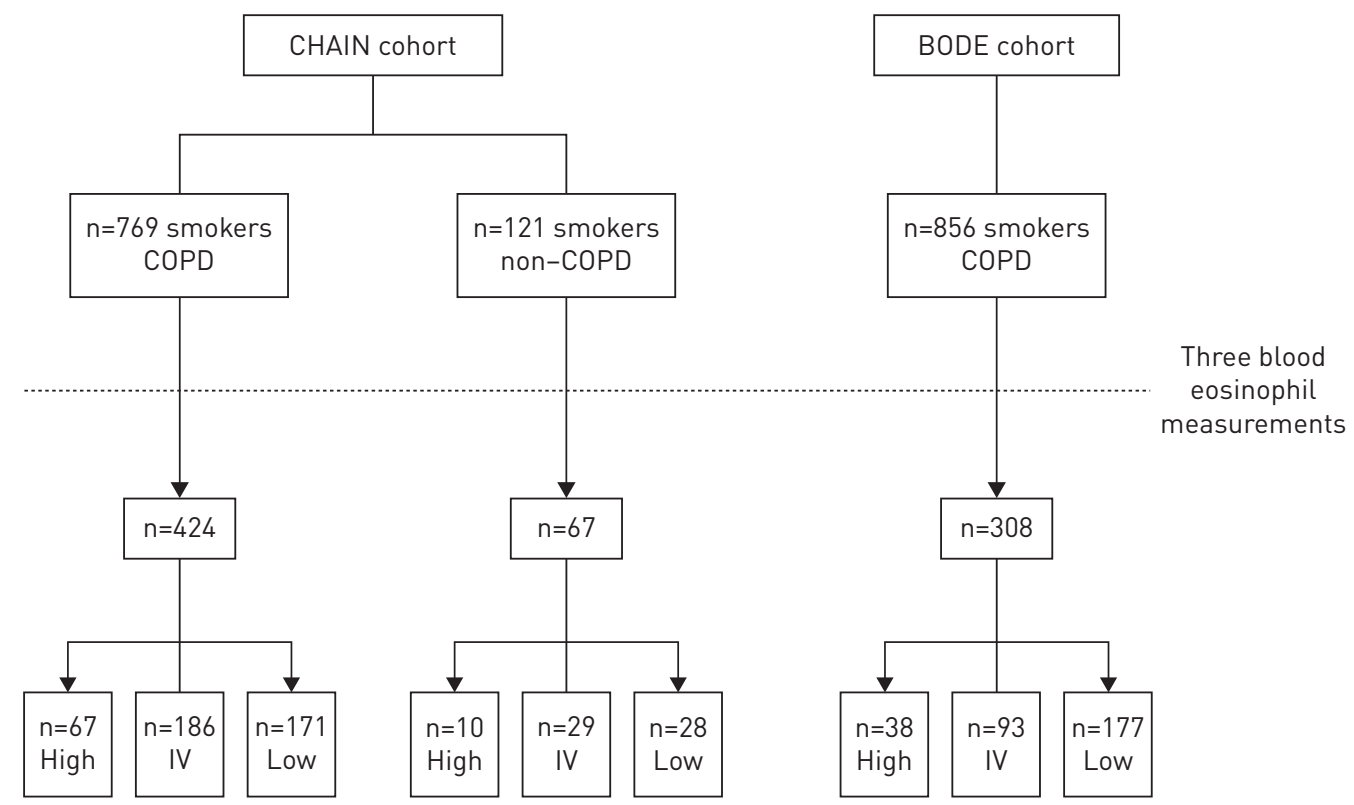

FIGURE 1 Flow diagram of subjects from the CHAIN and BODE cohorts. COPD: chronic obstructive pulmonary disease; high: persistently high eosinophil count $\left(\geqslant 300\right.$ cells $\left.\mu \mathrm{L}^{-1}\right)$; IV: intermittently variable eosinophil count (fluctuating between $\geqslant 300$ and $<300$ cells $\mu \mathrm{L}^{-1}$ ); low: persistently low eosinophil count $\left(<300\right.$ cells $\mu \mathrm{L}^{-1}$ ). 
There were 37 (8.7\%) deaths, of which 17 (9.9\%) had a persistently low eosinophil count, 17 (9.1\%) had an intermittently variable eosinophil count and three (4.5\%) had a persistently high eosinophil count.

In the BODE cohort, the median follow-up time after the three measurements of eosinophils was 130 (91170) months. During this period, there were 97 deaths: $62(34.4 \%)$ in patients with a persistently low eosinophil count, 29 (30.5\%) in patients with an intermittently variable eosinophil count and six (15.4\%)

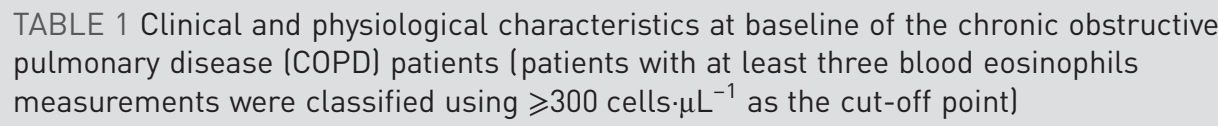

\section{CHAIN cohort}

Patients n

Male

Age year

Pack-years

Active smoking

BMI $\mathrm{kg} \cdot \mathrm{m}^{-2}$

FEV1 L

FEV $1 \%$ pred

$\mathrm{PaO}_{2} \mathrm{mmHg}$

FVC L

FVC \% pred

FEV $1 / F V C$

6MWD m

Dyspnoea mMRC

BODE index

IC/TLC

Kco \% pred

Charlson index

Inhaled anticholinergic

Inhaled $\beta_{2}$-agonist

Inhaled corticosteroid

CAT

History of asthma

$\lg$ E total U. $\mathrm{L}^{-1}$

BODE cohort

Patients $\mathrm{n}$

Male

Age years

Pack-years

Active smoking

BMI $\mathrm{kg} \cdot \mathrm{m}^{-2}$

FEV1 L

FEV $1 \%$ pred

FVC L

FVC \% pred

FEV 1 /FVC

6MWD m

Dyspnoea mMRC

BODE index

IC/TLC

Kco \% pred

Charlson index

Inhaled anticholinergic

Inhaled $\beta_{2}$-agonist

Inhaled corticosteroid

147
$125(85)$
$67 \pm 9$
$53 \pm 28$
32
$28.9 \pm 7.4$
$1.68 \pm 0.65$
$60 \pm 19$
$68.9 \pm 8.1$
$3.14 \pm 0.91$
$85 \pm 23$
$53 \pm 11$
$444 \pm 98$
$1(0-3)$
$2(0-6)$
$0.35 \pm 0.09$
$78 \pm 24$
$1(0-5)$
70
76
66
$11(2-27)$
2.5
$57(9-1121)$

82

70 (85)

$65 \pm 9$

$60 \pm 31$

34

$27.1 \pm 5.3$

$1.58 \pm 0.59$

$61 \pm 20$

$2.92 \pm 0.71$

$83 \pm 19$

$53 \pm 13$

$391 \pm 134$

$1(0-4)$

$1(0-5)$

$0.34 \pm 0.06$

$74 \pm 22$

$2(0-6)$

62

62

59
277

230183

$67 \pm 9$

$58 \pm 30$

26

$28.1 \pm 4.7$

$1.68 \pm 0.63$

$60 \pm 19$

$68.0 \pm 9.4$

$3.16 \pm 0.94$

$87 \pm 23$

$53 \pm 10$

$445 \pm 92$

$1(0-3)$

$1(0-5)$

$0.35 \pm 0.09$

$73 \pm 24$

1 (0-4)

73

75

68

$10(2-26)$

3.1

36 (6-506)

0.595

0.715

0.142

0.192

0.171

0.920

0.517

0.443

0.796

0.404

0.663

0.732

0.682

0.396

0.994

0.102

0.105

0.548

0.334

0.472

0.305

0.755

0.003

226

180 (80)

0.256

$65 \pm 9$

0.611

$61 \pm 33$

0.876

31

$27.1 \pm 5.1$

0.597

$1.54 \pm 0.64$

0.988

$59 \pm 22$

$3.01 \pm 0.84$

0.555

0.899

$85 \pm 24$

0.478

$409 \pm 119-0.269$

$1(0-3) \quad 0.066$

$1(0-6) \quad 0.116$

$0.33 \pm 0.11 \quad 0.976$

$73 \pm 20 \quad 0.510$

$1(0-4) \quad 0.216$

$64 \quad 0.760$

$63 \quad 0.824$

$57-0.773$

Data presented as $\mathrm{n}(\%)$, mean $\pm \mathrm{SD}, \%$ or median (5th-95th percentile), unless otherwise stated. BMI: body mass index; $\mathrm{FEV}_{1}$ : forced expiratory volume in $1 \mathrm{~s} ; \mathrm{PaO}_{2}$ : arterial oxygen tension; FVC: forced vital capacity; 6MWD: 6-min walk distance; mMRC: modified Medical Research Council; IC/TLC: inspiratory capacity/total lung capacity; Kco: transfer coefficient of the lung for carbon monoxide; CAT: COPD Assessment Test. 

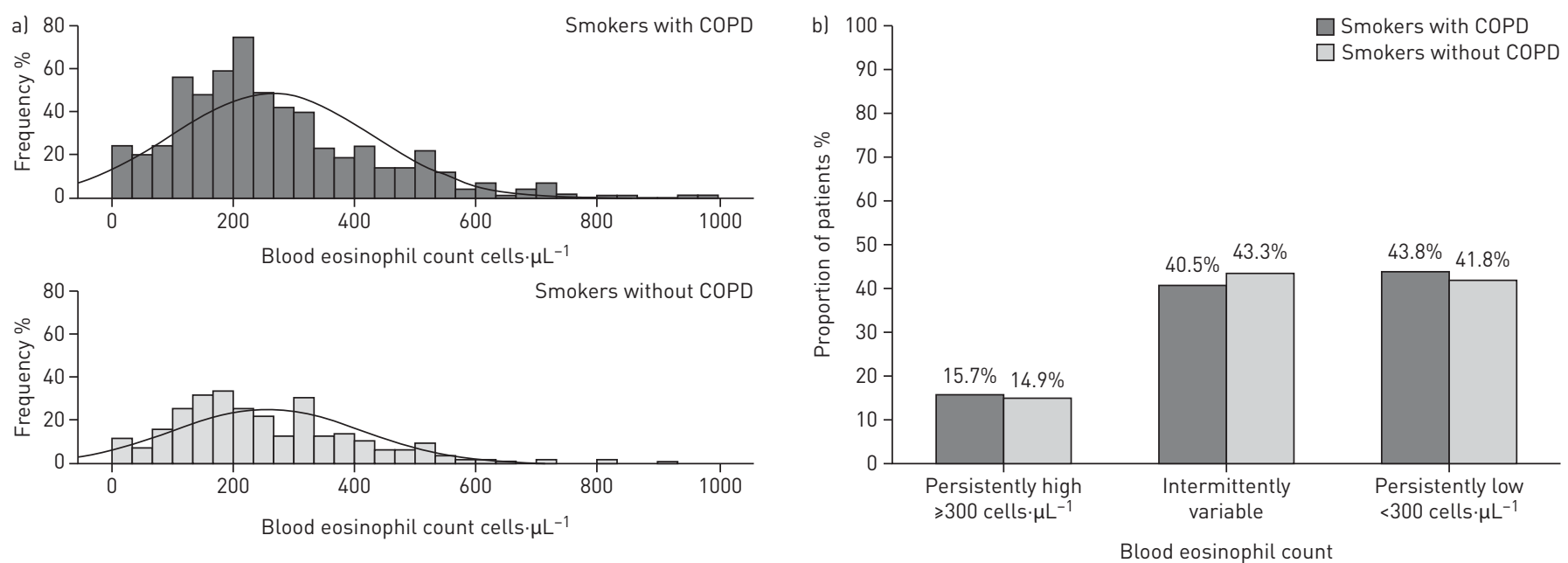

Blood eosinophil count

FIGURE 2 a) Distribution of blood eosinophil levels in smoker subjects with and without chronic obstructive pulmonary disease (COPD) in the CHAIN cohort at baseline. b) Longitudinal distribution of blood eosinophil levels in smoker subjects with and without COPD in the CHAIN cohort.

in patients with a persistently high eosinophil count $(\mathrm{p}=0.06)$ (figure 3 ). The statistical difference increased if the analysis performed compared patients with persistently high eosinophils versus the rest ( $15.8 \%$ versus $33.7 \%$; $\mathrm{p}=0.026$ ). When the analysis was repeated using $\geqslant 250$ cells $\mu \mathrm{L}^{-1}$ as the threshold, the difference persisted ( $14 \%$ versus $34.3 \% ; \mathrm{p}=0.008)$. Once the eosinophil threshold was raised to

TABLE 2 Baseline characteristics of blood eosinophil longitudinal patterns in patients with chronic obstructive pulmonary disease (COPD) (CHAIN cohort) using $\geqslant 300$ cells $\mu \mathrm{L}^{-1}$ as the cut-off point

\begin{tabular}{|c|c|c|c|c|}
\hline & $\begin{array}{l}\text { Persistently high } \\
\geqslant 300 \text { cells } \cdot \mu \mathrm{L}^{-1}\end{array}$ & $\begin{array}{l}\text { Intermittently } \\
\text { variable }\end{array}$ & $\begin{array}{l}\text { Persistently low } \\
<300 \text { cells } \mu \mathrm{L}^{-1}\end{array}$ & p-value \\
\hline Patients n & 67 & 186 & 171 & \\
\hline Male & $60(90)$ & $156(84)$ & $139(81)$ & 0.298 \\
\hline Age years & $66 \pm 8$ & $68 \pm 9$ & $67 \pm 9$ & 0.148 \\
\hline Pack-years & $55 \pm 29$ & $55 \pm 28$ & $57 \pm 31$ & 0.779 \\
\hline Active smoking & 31 & 29 & 27 & 0.729 \\
\hline BMI $\mathrm{kg} \cdot \mathrm{m}^{-2}$ & $29.8 \pm 5.5$ & $28.2 \pm 4.9$ & $28.2 \pm 4.7$ & 0.114 \\
\hline FEV 1 L & $1.80 \pm 0.63$ & $1.63 \pm 0.64$ & $1.69 \pm 0.62$ & 0.150 \\
\hline FEV $1 \%$ pred & $61 \pm 18$ & $60 \pm 20$ & $60 \pm 19$ & 0.949 \\
\hline $\mathrm{PaO}_{2} \mathrm{mmHg}$ & $69.6 \pm 7.4$ & $67.5 \pm 9.0$ & $68.9 \pm 9.3$ & 0.446 \\
\hline FVC L & $3.37 \pm 0.94$ & $3.08 \pm 0.92$ & $3.15 \pm 0.93$ & 0.094 \\
\hline FVC $\%$ pred & $87 \pm 22$ & $86 \pm 24$ & $86 \pm 22$ & 0.974 \\
\hline FEV $1 / F V C$ & $54 \pm 11$ & $53 \pm 11$ & $54 \pm 10$ & 0.704 \\
\hline 6MWD m & $461 \pm 95$ & $438 \pm 99$ & $451 \pm 89$ & 0.175 \\
\hline Dyspnoea mMRC & $1(0-3)$ & $1(0-4)$ & $1(0-3)$ & 0.212 \\
\hline BODE index & $1(0-5)$ & $2(0-6)$ & $1(0-5)$ & 0.346 \\
\hline IC/TLC & $0.36 \pm 0.09$ & $0.34 \pm 0.09$ & $0.35 \pm 0.09$ & 0.091 \\
\hline Kco \% pred & $82 \pm 25$ & $73 \pm 23$ & $74 \pm 24$ & 0.059 \\
\hline Charlson index & $1(0-5)$ & $1(0-4)$ & $1(0-4)$ & 0.158 \\
\hline Inhaled anticholinergic & 64 & 76 & 71 & 0.172 \\
\hline Inhaled $\beta_{2}$-agonist & 73 & 75 & 70 & 0.483 \\
\hline Inhaled corticosteroid & 64 & 68 & 59 & 0.233 \\
\hline CAT & $11(1-27)$ & $12(2-27)$ & $10(2-24)$ & 0.297 \\
\hline $\lg E$ total U.L $\mathrm{L}^{-1}$ & $50(8-1158)$ & $62(7-690)$ & $26(5-504)$ & $<0.001$ \\
\hline \multicolumn{5}{|c|}{$\begin{array}{l}\text { Data presented as } \mathrm{n}(\%) \text {, mean } \pm \mathrm{SD}, \% \text { or median }(5 \mathrm{th}-95 \text { th percentile), unless otherwise stated. BMI: body } \\
\text { mass index; FEV1: forced expiratory volume in } 1 \mathrm{~s} ; \mathrm{PaO}_{2} \text { : arterial oxygen tension; FVC: forced vital capacity; } \\
\text { 6MWD: 6-min walk distance; mMRC: modified Medical Research Council; IC/TLC: inspiratory capacity/total } \\
\text { lung capacity; Kco: transfer coefficient of the lung for carbon monoxide; CAT: COPD Assessment Test. }\end{array}$} \\
\hline
\end{tabular}


TABLE 3 Baseline characteristics of blood eosinophil longitudinal patterns in patients with chronic obstructive pulmonary disease (BODE cohort) using $\geqslant 300$ cells $\mu \mathrm{L}^{-1}$ as the cut-off point

\begin{tabular}{|c|c|c|c|c|}
\hline & $\begin{array}{l}\text { Persistently high } \\
\geqslant 300 \text { cells } \cdot \mu \mathrm{L}^{-1}\end{array}$ & $\begin{array}{l}\text { Intermittently } \\
\text { variable }\end{array}$ & $\begin{array}{l}\text { Persistently low } \\
<300 \text { cells } \cdot \mu \mathrm{L}^{-1}\end{array}$ & p-value \\
\hline Patients n & 38 & 93 & 177 & \\
\hline Male & $30(79)$ & $76(82)$ & $143(81)$ & 0.930 \\
\hline Age years & $63 \pm 8$ & $66 \pm 9$ & $65 \pm 9$ & 0.386 \\
\hline Pack-years & $64 \pm 33$ & $59 \pm 30$ & $61 \pm 33$ & 0.701 \\
\hline Active smoking & 42 & 33 & 29 & 0.298 \\
\hline $\mathrm{BMI} \mathrm{kg} \cdot \mathrm{m}^{-2}$ & $28.2 \pm 6.1$ & $28.2 \pm 4.9$ & $27.8 \pm 4.7$ & 0.655 \\
\hline FEV 1 L & $1.58 \pm 0.53$ & $1.52 \pm 0.56$ & $1.56 \pm 0.68$ & 0.877 \\
\hline FEV $_{1} \%$ pred & $60 \pm 18$ & $60 \pm 22$ & $59 \pm 22$ & 0.959 \\
\hline FVC L & $2.92 \pm 0.76$ & $3.02 \pm 0.80$ & $2.98 \pm 0.85$ & 0.839 \\
\hline FVC $\%$ pred & $84 \pm 18$ & $84 \pm 22$ & $85 \pm 24$ & 0.874 \\
\hline $\mathrm{FEV}_{1} / \mathrm{FVC}$ & $53 \pm 12$ & $51 \pm 13$ & $50 \pm 13$ & 0.289 \\
\hline 6MWD m & $397 \pm 131$ & $379 \pm 132$ & $418 \pm 115$ & 0.058 \\
\hline Dyspnoea mMRC & $1(0-4)$ & $1(0-4)$ & $1(0-3)$ & 0.340 \\
\hline BODE index & $1(0-7)$ & $1(0-6)$ & $1(0-6)$ & 0.384 \\
\hline IC/TLC & $0.34 \pm 0.05$ & $0.34 \pm 0.11$ & $0.33 \pm 0.11$ & 0.913 \\
\hline Kco \% pred & $74 \pm 23$ & $74 \pm 20$ & $72 \pm 20$ & 0.718 \\
\hline Charlson index & $2(0-4)$ & $1(0-5)$ & $1(0-4)$ & 0.624 \\
\hline Inhaled anticholinergic & 60 & 65 & 65 & 0.853 \\
\hline Inhaled $\beta_{2}$-agonist & 65 & 58 & 65 & 0.529 \\
\hline Inhaled corticosteroid & 65 & 55 & 58 & 0.563 \\
\hline
\end{tabular}

Data presented as $\mathrm{n}(\%)$, mean \pm SD, $\%$ or median (5th-95th percentile), unless otherwise stated. BMI: body mass index; FEV1: forced expiratory volume in $1 \mathrm{~s}$; FVC: forced vital capacity; 6MWD: 6-min walk distance; mMRC: modified Medical Research Council; IC/TLC: inspiratory capacity/total lung capacity; Kco: transfer coefficient of the lung for carbon monoxide.

350 cells $\mu \mathrm{L}^{-1}$, the proportion was similar $(14.3 \%$ versus $32.3 \%)$, but it was no longer significant $(\mathrm{p}=0.239)$ due to the low number of patients above this threshold.

The Kaplan-Meier analysis for all-cause mortality showed that an eosinophil count $<300 \mathrm{cells} \cdot \mu \mathrm{L}^{-1}$ was associated with a shorter survival time (174 months, 95\% CI 165-183) than an eosinophil count

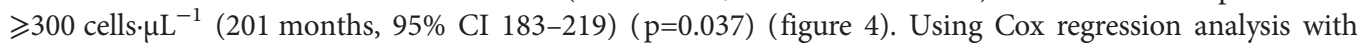
eosinophils $<300$ cells $\cdot \mu \mathrm{L}^{-1}$ as the cut-off value, the hazard ratio for all-cause mortality was 2.344 (95\% CI 1.026-5.355; $\mathrm{p}=0.043$ ), and 7.287 (95\% CI 1.004-52.891) ( $\mathrm{p}=0.050)$ after adjusting for sex, age, body mass index, FEV1 \% pred and Charlson index (table 4).

\section{Discussion}

This longitudinal study of blood eosinophil levels in two observational cohorts of COPD patients attending pulmonary clinics and a group of smokers without COPD as controls yielded several important

FIGURE 3 Blood eosinophil longitudinal pattern and mortality in the BODE cohort.

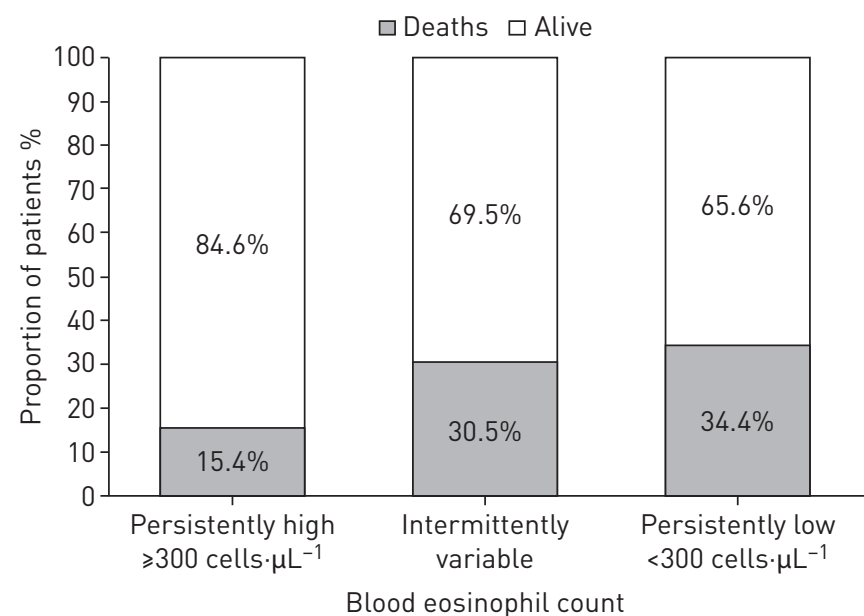


FIGURE 4 Kaplan-Meier analysis for all-cause mortality. An eosinophil count $<300$ cells $\mu \mathrm{L}^{-1}$ was associated with a shorter survival time than an eosinophil count $\geqslant 300$ cells. $\mu \mathrm{L}^{-1}$ ( $p_{\text {log-rank }}=0.037$ ) in the BODE cohort.

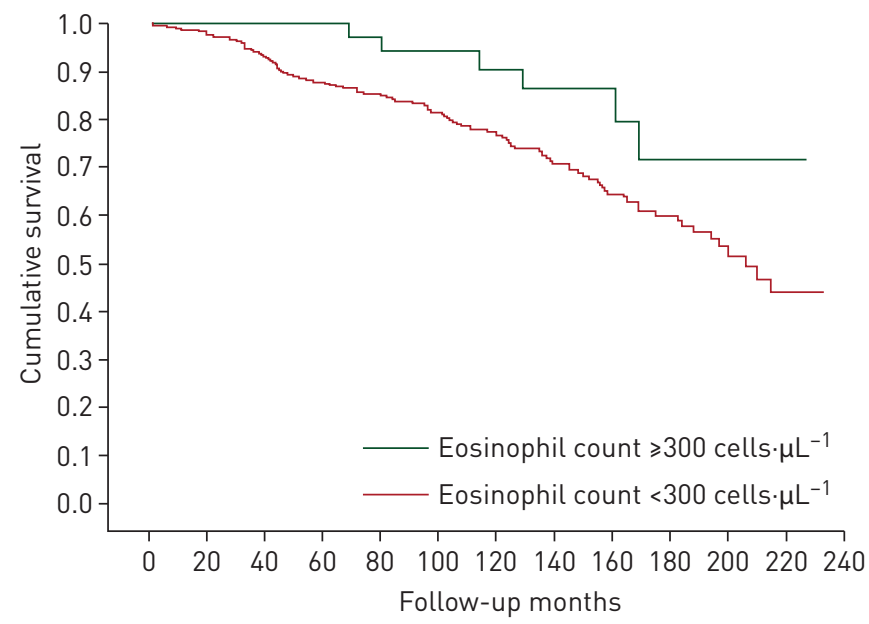

findings. First, the pattern and distribution of eosinophils over time were similar in patients with COPD and smoking subjects without disease. The proportion of patients and smoker subjects without COPD with persistent high blood eosinophils $\left(\geqslant 300\right.$ cells $\left.\mu \mathrm{L}^{-1}\right)$ was $\sim 15 \%$ in both groups. Second, in the COPD population, there was an important annual variability in the eosinophil count. Third, there were no significant differences in clinical and physiological characteristics among the patients with and without persistent blood eosinophilia. A persistently high blood eosinophil level $\left(\geqslant 300 \mathrm{cells} \cdot \mu \mathrm{L}^{-1}\right)$ was not associated with an increased exacerbation rate, but rather with a lower risk of death.

The identification of biomarkers in COPD has generated interest in an attempt to develop personalised management of this disease. So far, no biomarker alone or in combination has proven reliable enough to use in clinical practice [22]. Recently, circulating eosinophils have emerged as a potential biomarker in selected patients, based on the observation that the level of a single blood eosinophil count appears to be associated with subsequent risk for exacerbation and to predict the response to ICS therapy in clinical trials [8-12]. This is in contrast to the findings of the ECLIPSE (Evaluation of COPD Longitudinally to Identify Predictive Surrogate End-points) observational study which found that $36 \%$ of the patients had blood eosinophil counts persistently $\geqslant 2 \%$, and these patients had higher FEV1, and lower St George's Respiratory Questionnaire and mMRC scores. Interestingly, the proportion of patients $\geqslant 2 \%$ was similar to that seen in the healthy subjects in the same cohort [6]. The stratification of patients using $2 \%$ and $\geqslant 150$ cells $\mu \mathrm{L}^{-1}$ cut-off values has been justified because this threshold seemed to identify patients more likely to exacerbate in the post hoc analysis of clinical trials $[5,9-11,23]$.

\section{Prevalence and longitudinal levels of eosinophils}

We selected the level of 300 cells. $\mu \mathrm{L}^{-1}$ to anchor this study because cohort reports $[13,24]$ and analysis from trials $[8,12]$ and asthma-COPD overlap consensus [25] support the use of higher thresholds in patients with COPD. We found that blood eosinophil count at baseline and its longitudinal variability over 2 years were similar between smokers with and without COPD (figure $2 \mathrm{a}$ and $\mathrm{b}$ ). As a healthy control population was not included in the design of CHAIN, we cannot interpret whether the eosinophilia observed is associated with smoking itself, but our results suggest that the circulating levels and

TABLE 4 Cox regression analysis ${ }^{\#}$ for risk of death in patients with chronic obstructive pulmonary disease with eosinophils (300 cells $\mu \mathrm{L}^{-1}$ cut-off value), adjusted for longitudinal eosinophil pattern, age, sex, body mass index (BMI), forced expiratory volume in $1 \mathrm{~s}$ (FEV1) \% pred and Charlson index

\begin{tabular}{|c|c|c|}
\hline & Hazard ratio $(95 \% \mathrm{CI})$ & $\mathrm{p}$-value \\
\hline Eosinophils $<300$ cells $\mu \mathrm{L}^{-1 \pi}$ & $7.287(1.004-52.891)$ & 0.050 \\
\hline Age (each 1 year more) & $1.073(1.043-1.105)$ & $<0.001$ \\
\hline BMI (each $1 \mathrm{~kg} \cdot \mathrm{m}^{-2}$ lower) & $1.100(1.038-1.162)$ & 0.001 \\
\hline FEV1 \% pred (each $1 \%$ lower) & $1.015(1.003-1.029)$ & 0.017 \\
\hline
\end{tabular}

\footnotetext{
\# : backward stepwise method and Wald's criteria/three iterations; ": persistently lower eosinophil pattern.
} 
distribution of eosinophils are not associated with the diagnosis of COPD. Furthermore, using a threshold of eosinophilia at 150 cells $\mu \mathrm{L}^{-1}$ did not change the results reported (supplementary table S2).

The few studies that have evaluated the levels of eosinophils in COPD patients over time have observed significant instability $[24,26]$. In our study, only a small proportion $(15 \%)$ of the patients had persistently high eosinophils over the period of observation, while $41 \%$ of the patients fluctuated above and below this threshold, a proportion that is relatively high to use as a single measurement of eosinophils as a clinical biomarker. Indeed, experts in the field of eosinophilic syndromes require repeated elevated measurements over 6 months to meet the criteria for the diagnosis of eosinophilic diseases [14]. Unlike OshaGbemi et al. [26], we did not observe differences with the control group of smokers without COPD (figure $2 \mathrm{~b}$ ). The differences between study results could be explained by the fact that the report by OshaGBemi et al. [26] was population-based (diagnosis of COPD without spirometry) and 50\% of the subjects were never-smokers.

\section{Eosinophils and outcomes in COPD}

The lung function tests, arterial blood gases, 6MWD, health status, perception of dyspnoea, comorbidities and BODE index were similar in the patients irrespective of eosinophil level or longitudinal eosinophil level behaviour (tables 1-3). After the observation period used to establish the stability of the signal, there were no differences among the groups in exacerbations or hospitalisation rates due to exacerbations in the subsequent median period of 12 months of follow-up. This was not due to the potential differential effect of uneven use of medication, because the proportion of medications documented was similar in all groups (table 2). In addition, it has been shown that the use of ICSs does not affect blood levels of eosinophils at the pharmacological doses used [27, 28]. Furthermore, in the CHAIN and BODE cohorts, the prevalence of ICS use was similar in patients with persistently high, intermittently variable or persistently low eosinophil counts (supplementary table S2), thus negating an effect of use of ICSs on the findings reported here. The lack of a relationship between eosinophil level and outcomes is similar to the results reported by Zysman et al. [29], who followed 458 patients with COPD for an average of 3 years. They observed no difference in exacerbation rates of asthma or COPD exacerbations irrespective of the threshold of eosinophils used for the analysis.

The longitudinal observation of patients in the BODE cohort allowed us to evaluate the relationship between eosinophil levels and survival. To our surprise, patients with persistently elevated eosinophils over 2 years had a significantly lower risk of death than those whose levels were lower than the predetermined threshold of 300 cells $\mu \mathrm{L}^{-1}$. We repeated the analysis using thresholds of 250 and 350 cells $\mu \mathrm{L}^{-1}$ and the findings remained unchanged, providing evidence that this was not due to the arbitrary threshold chosen. These findings are in agreement with those of SuzuKi et al. [24], who reported that COPD patients without clinically diagnosed asthma who had two or more asthma-like features had better outcome and lower mortality than those without that asthma phenotype. In the SUZUKI et al. [24] study, blood eosinophils $\geqslant 300$ cells $\mu \mathrm{L}^{-1}$ by itself failed to reach statistical significance, likely due to the small sample size of that cohort. Our study, larger in size, was capable of detecting a significant signal. There is no easy explanation for this finding, but a recent post hoc meta-analysis showed that patients with COPD with lower blood eosinophil counts $(<2 \%)$ had more pneumonias than those with higher counts [30]. Together, this information suggests that caution should be taken to determine the appropriate pathological threshold of eosinophils in COPD before we use the eosinophil count as a biomarker of poor prognosis and/or for specific therapeutic interventions.

This study has several strengths. It included a large number of well-characterised patients being treated for COPD in pulmonary clinics in two countries and its "real-life" nature allowed the sequential measurement of blood counts in regular laboratories, as is available to clinicians. Finally, the long follow-up time provides invaluable information on outcomes, not usually available in most pharmacological trials. Our study also had several limitations. First, the CHAIN and BODE cohorts are observational studies not constituted of patients recruited from a general medical practice or a population-based study. Therefore, they may not represent the distribution of COPD severity in the general population. However, both cohorts included a broad range of disease severity. Second, most of the participants were men, although over 130 women were included in the analysis and the distribution of women was similar in the different eosinophil longitudinal patterns. Third, the lack of a healthy (nonsmoker) control group did not allow us to evaluate if blood eosinophils could be related to the smoking habit itself. However, this was not the main objective of this study. Finally, the BODE cohort did not include repeated eosinophil blood measurements in all of the patients recruited. However, this cohort is large and well characterised, recruited by a team with experience in COPD and a long-term follow-up providing an adequate number of patients with three measurements and enough deaths to enhance the mortality analysis.

In summary, data on two large cohorts of well-characterised COPD patients show that in three measurements of blood eosinophils measured over 2 years, there is important variability in blood levels of 
eosinophils, with only $15 \%$ of patients showing a persistently high blood eosinophil count $\left(\geqslant 300\right.$ cells $\left.\mu \mathrm{L}^{-1}\right)$. The prevalence and stability is similar to that seen in smokers without COPD. A persistent high eosinophil level did not confer an increased risk of exacerbations or hospitalisations in the patients with COPD, but was rather associated with a survival benefit. Further studies in other populations should validate our results.

\section{Acknowledgements}

We would like to thank AstraZeneca (Madrid, Spain) for their financial support of this study. The funders had no role in study design, data collection and analysis, decision to publish or preparation of the manuscript.

The COPD PII of SEPAR (Sociedad Española de Neumología y Cirugía Torácica) endorsed this study.

Author contributions: C. Casanova contributed to the conception and design, recruitment of patients, data analysis and interpretation, and drafting the manuscript for important intellectual content. B.R. Celli contributed to the conception and design, data analysis and interpretation, and drafting the manuscript for important intellectual content. J.M. Marin, J.P. de-Torres, B. G. Cosio, V. Pinto-Plata and M. Divo contributed to conception, recruitment of patients, data analysis and interpretation, and drafting the manuscript. J.L. López-Campos, J.B. Soriano and J.J. Soler-Cataluña contributed to drafting the manuscript. J.B. Soriano is a Methodological Consultant of SEPAR. The rest of the authors contributed to recruitment of patients.

\section{References}

1 Vestbo J, Hurd SS, Agusti AG, et al. Global strategy for the diagnosis, management, and prevention of chronic obstructive pulmonary disease: GOLD executive summary. Am J Respir Crit Care Med 2013; 187: 347-365.

2 Han MK, Agusti A, Calverley PM, et al. Chronic obstructive pulmonary disease phenotypes: the future of COPD. Am J Respir Crit Care Med 2010; 182: 598-604.

3 Miravitlles M, Soler-Cataluña JJ, Calle M, et al. Spanish Guidelines for Management of Chronic Obstructive Pulmonary Disease (GesEPOC) 2017. Pharmacological treatment of stable phase. Arch Bronconeumol 2017; 53: 324-335.

4 Brightling CE, McKenna S, Hargadon B, et al. Sputum eosinophilia and the short term response to inhaled mometasone in chronic obstructive pulmonary disease. Thorax 2005; 60: 193-198.

5 Bafadhel M, McKenna S, Terry S, et al. Acute exacerbations of chronic obstructive pulmonary disease: identification of biologic clusters and their biomarkers. Am J Respir Crit Care Med 2011; 184: 662-671.

6 Singh D, Kolsum U, Brightling CE, et al. Eosinophilic inflammation in COPD: prevalence and clinical characteristics. Eur Respir J 2014; 44: 1697-1700.

7 Negewo NA, McDonald VM, Baines KJ, et al. Peripheral blood eosinophils: a surrogate marker for airway eosinophilia in stable COPD. Int J Chron Obstruct Pulmon Dis 2016; 11: 1495-1504.

8 Siddiqui SH, Guasconi A, Vestbo J, et al. Blood eosinophils: a biomarker of response to extrafine beclomethasone/ formoterol in chronic obstructive pulmonary disease. Am J Respir Crit Care Med 2015; 192: 523-525.

9 Pascoe S, Locantore N, Dransfield MT, et al. Blood eosinophil counts, exacerbations, and response to the addition of inhaled fluticasone furoate to vilanterol in patients with chronic obstructive pulmonary disease: a secondary analysis of data from two parallel randomised controlled trials. Lancet Respir Med 2015; 3: 435-442.

10 Pavord ID, Lettis S, Locantore N, et al. Blood eosinophils and inhaled corticosteroid/long-acting $\beta$-2 agonist efficacy in COPD. Thorax 2016; 71: 118-125.

11 Barnes NC, Sharma R, Lettis S, et al. Blood eosinophils as a marker of response to inhaled corticosteroids in COPD. Eur Respir J 2016; 47: 1374-1382.

12 Watz $\mathrm{H}$, Tetzlaff $\mathrm{K}$, Wouters EF, et al. Blood eosinophil count and exacerbations in severe chronic obstructive pulmonary disease after withdrawal of inhaled corticosteroids: a post-hoc analysis of the WISDOM trial. Lancet Respir Med 2016; 4: 390-398.

13 Vedel-Krogh S, Nielsen SF, Lange P, et al. Blood eosinophils and exacerbations in chronic obstructive pulmonary disease. The Copenhagen General Population Study. Am J Respir Crit Care Med 2016; 193: 965-974.

14 Hogan SP, Rosenberg HF, Moqbel R, et al. Eosinophils: biological properties and role in health and disease. Clin Exp Allergy 2008; 38: 709-750.

15 López-Campos JL, Peces-Barba G, Soler-Cataluña JJ, et al. Chronic obstructive pulmonary disease history assessment in Spain: a multidimensional chronic obstructive pulmonary disease evaluation. Study methods and organization. Arch Bronconeumol 2012; 48: 453-459.

16 Celli BR, Cote C, Marin JM, et al. The body-mass index, airflow obstruction, dyspnea, and exercise capacity index in chronic obstructive pulmonary disease. N Engl J Med 2004; 350: 1005-1012.

17 American Thoracic Society. Lung function testing: selection of reference values and interpretative strategies. $A m$ Rev Respir Dis 1991; 144: 1202-1218.

18 Macintyre N, Crapo RO, Viegi G, et al. Standardisation of the single-breath determination of carbon monoxide uptake in the lung. Eur Respir J 2005; 26: 720-735.

19 American Thoracic Society. Guidelines for the six-minute walk test. Am J Respir Crit Care Med 2002; 166: $111-117$

20 Mahler DA, Weels CK. Evaluation of clinical methods for rating dyspnea. Chest 1988; 93: 580-586.

21 Charlson ME, Pompei P, Ales KL, et al. A new method of classifying prognostic comorbidity in longitudinal studies: development and validation. J Chronic Dis 1987; 40: 373-383.

22 Sin DD, Hollander Z, DeMarco ML, et al. Biomarker development for chronic obstructive pulmonary disease. from discovery to clinical implementation. Am J Respir Crit Care Med 2015; 192: 1162-1170.

23 Marks-Konczalik J, Costa M, Robertson J, et al. A post-hoc subgroup analysis of data from a six-month clinical trial comparing the efficacy and safety of losmapimod in moderate-severe COPD patients with $\leqslant 2 \%$ and $>2 \%$ blood eosinophils. Respir Med 2015; 109: 860-869.

24 Suzuki M, Makita H, Konno S, et al. Asthma-like features and clinical course of chronic obstructive pulmonary disease. an analysis from the Hokkaido COPD Cohort Study. Am J Respir Crit Care Med 2016; 194: 1358-1365.

25 Sin DD, Miravitlles M, Mannino DM, et al. What is asthma-COPD overlap syndrome? Towards a consensus definition from a round table discussion. Eur Respir J 2016; 48: 664-673. 
26 Oshagbemi OA, Burden AM, Braeken DCW, et al. Stability of blood eosinophils in patients with chronic obstructive pulmonary disease and in control subjects, and the impact of sex, age, smoking, and baseline counts. Am J Respir Crit Care Med 2017; 195: 1402-1404.

27 Meijer RJ, Kerstjens AM, Arends RL, et al. Effect of inhaled fluticasone and oral prednisolone on clinical and inflammatory parameters in patients with asthma. Thorax 1999; 54: 894-899.

28 Kreindler JL, Watkins ML, Lettis S, et al. Effect of inhaled corticosteroids on blood eosinophil count in steroid-naïve patients with COPD. BMJ Open Respir Res 2016; 3: e000151.

29 Zysman M, Deslee G, Caillaud D, et al. Relationship between blood eosinophils, clinical characteristics, and mortality in patients with COPD. Int J Chron Obstruct Pulmon Dis 2017; 12: 1819-1824.

30 Pavord ID, Lettis S, Anzueto A, et al. Blood eosinophil count and pneumonia risk in patients with chronic obstructive pulmonary disease: a patient-level meta-analysis. Lancet Respir Med 2016; 4: 731-741. 